\title{
Fus Expression Patterns in Developing Tooth
}

\author{
Eun-Jung Kim ${ }^{1 *}$, Jong-Min Lee ${ }^{1^{*}}$ and ${ }^{\dagger}$ Han-Sung Jung ${ }^{1,2}$ \\ ${ }^{1}$ Division in Anatomy and Developmental Biology, Department of Oral Biology, \\ Research Center for Orofacial Hard Tissue Regeneration, Brain Korea 21 Project, \\ Oral Science Research Center, College of Dentistry, Yonsei University, Seoul 120-752, Republic of Korea \\ ${ }^{2}$ Oral Biosciences, Faculty of Dentistry, The University of Hong Kong, Hong Kong SAR
}

\begin{abstract}
Recently, the RNA/DNA-binding protein FUS, Fused in sarcoma, was shown to play a role in growth, differentiation, and morphogenesis in vertebrates. Because little is known about Fus, we investigated its expression pattern in murine tooth development. In situ hybridization of mouse mandibles at specific developmental stages was performed with a DIG-labeled RNA probe. During early tooth development, Fus was detected in the dental epithelium and dental mesenchyme at 11 days postcoitum (dpc) and 12 dpc. From 14 dpc, Fus was strongly expressed in the dental papilla and the cervical loop of the dental epithelium. At postnatal day 4 (PN4), Fus expression was observed in the odontoblasts, ameloblasts, the proliferation zone of the pulp, and the cervical loop. At PN14, the expression pattern of Fus was found to be maintained in the odontoblasts and the proliferation zone of the pulp. Furthermore, Fus expression was especially strong in the Hertwig's epithelial root sheath (HERS). Therefore, this study suggests that Fus may play a role in the HERS during root development.
\end{abstract}

Key words : Fus, Tooth, Hertwig's epithelial root sheath, In situ hybridization

\section{INTRODUCTION}

During embryogenesis, developmental regulators, such as growth factors, transcription factors, and RNA-binding proteins, control the processes of growth, differentiation, and morphogenesis, which shape and pattern to the growing embryo. Many studies have focused on the role of RNAbinding proteins in growth, differentiation, and morphogenesis in vertebrates (Tanaka et al., 1997; Wakamatsu \& Weston, 1997; Wu et al., 1997; Peng et al., 2000; Gerber et al., 2002).

Fused in sarcoma (Fus), also known as translocated in liposarcoma (TLS), POMP75, and pigpen, is a nuclear DNA/RNA-binding protein that regulates the different steps of gene expression, including transcription, splicing, and mRNA transport (Dormann et al., 2013). FUS not only regulates gene expression in the nucleus but also exerts important functions in the cytoplasm. FUS has been suggested to continuously shuttle between the nucleus and cytoplasm (Zinszner et al., 1997).

The N-terminus of FUS appears to be involved in transcriptional activation, while the C-terminus is involved in protein and RNA binding. In addition, recognition sites for the transcription factors AP2, GCF, and Sp1 have been identified in FUS (Aman et al., 1996). FUS/ TLS is a member of the TET protein family, which also includes EWS, the TATA-binding protein (TBP)-associated

\footnotetext{
Manuscript received 21 August 2013, Received in revised form 28 August 2013, Accepted 3 September 2013

*Eun-Jung Kim and Jong-Min Lee contributed equally to this work.

${ }^{\dagger}$ Corresponding Author : Han-Sung Jung, Division in Anatomy and Developmental Biology, Department of Oral Biology, College of Dentistry, Yonsei University, 50 Yonsei-ro, Seodaemoon-gu, Seoul 120-752, Republic of Korea. Tel. : +82-2-2228-3065, Fax : +82-2-312-8012, E-mail : hsjung@yuhs.ac This is an Open Access article distributed under the terms of the Creative Commons Attribution Non-Commercial License(http://creativecommons.org/ licenses/by-nc/3.0) which permits unrestricted non-commercial use, distribution, and reproduction in any medium, provided the original work is properly cited.
} 
factor TAFII68/TAF15 and the Drosophila protein cabeza/ SARF (Morohoshi et al., 1998; Bertolotti et al., 1999). Fus was identified approximately 20 years ago as a fusion oncogene in human myxoid liposarcoma (Crozat et al., 1993; Rabbitts et al., 1993). In this cancer, an aberrant chromosomal translocation fuses the N-terminus of FUS to a transcription factor, such as CHOP, giving rise to a fusion oncogene. Fus has been examined in various studies of neurodegeneration; mutations in FUS were reported to cause familial ALS, and FUS was found to be deposited in pathological protein inclusions (Kwiatowski et al., 2009; Vance et al., 2009).

Based on knockout studies, mice homozygous for the Fus mutation fail to suckle and die within 16 hours of birth. Fus-' - mice appear to develop normally, and histologic examination of serial sections confirms the normal structure and development of all major organs and tissues in these animals. However, the thymus is reduced in size in Fus- ${ }^{-}$ embryos, and the peripheral blood of newborn Fus-' mice shows a reduced number of white blood cells. In addition, Fus-' - mice have diminished cellularity in their lymphoid organs (Hicks et al., 2000). Furthermore, bovine pigpen (Fus) has been suggested to be involved endothelial cell proliferation and differentiation (Alliegro \& Alliegro, 1996). Pigpen mRNA and protein are expressed in endothelial cells. In a functional study, the nuclear injection of anti-pigpen antibodies was found to block endothelial cell division (Alliegro \& Alliegro, 2002), and this study suggested that pigpen may play a role in regulating endothelial cell growth and differentiation.

Teeth are one of the most diverse organs in vertebrates, both morphologically and functionally. An early signaling event during tooth development is the induction of the mesenchyme by bone morphogenic protein (BMP) and fibroblast growth factor (FGF) from the epithelium. BMP and FGF induce the expression of several mesenchymal transcription factors, many of which are necessary for sequential tooth development (Thesleff et al., 2003). Thus, teeth provide an excellent model to study vertebrate organogenesis. Furthermore, tooth root development is also regulated by reciprocal interactions between epithelial and mesenchymal tissues, such as in crown development (Thesleff \& Sharpe, 1997; Thesleff, 2000; Zhang et al., 2000;). After the crown formation stage, the Hertwig's epithelial root sheath (HERS) is a proliferated epithelial cell at the cervical loop of the enamel organ in the developing tooth (Hosoya et al., 2009). It is composed of an epithelial bilayer derived from the inner and outer enamel epithelium that fuses below the level of the cervical loop of the crown. Although a considerable amount of data exists on the expression of many genes during tooth development, the precise gene expression pattern of Fus mRNA during tooth development has not been extensively studied, especially during tooth root development. In this study, we analyzed the expression pattern of Fus mRNA during tooth development by in situ hybridization.

\section{MATERIALS AND METHODS}

All experiments were performed according to the guidelines of the Yonsei University, College of Dentistry, Intramural Animal Use and Care Committee.

\section{Animals}

Adult ICR mice were housed in a temperature-controlled room $\left(22^{\circ} \mathrm{C}\right)$ under artificial illumination (lights on from 05:00 to $17: 00$ ) at a relative humidity of $55 \%$ with access to food and water ad libitum. Embryos were obtained from time-mated pregnant mice. First mandible molar tooth germs of ICR mice at 11 dpc (days postcoitum), 12 dpc, 14 dpc, 16 dpc, postnatal day 4 (PN4), and PN14 were used for in situ hybridization and hematoxylin and eosin (HE) staining. Briefly, mandibles from each stage were fixed with $4 \%$ paraformaldehyde (PFA) in $0.01 \mathrm{M}$ phosphate- buffered saline (PBS, pH 7.4) overnight at $4^{\circ} \mathrm{C}$. After embedding the samples in paraffin, they were sectioned at a thickness of 5 .

\section{Section in situ hybridization}

In situ hybridization of the mouse mandible sections 
was performed using standard protocols (Eblaghie et al., 2004). The sections were baked at $65^{\circ} \mathrm{C}$, de-waxed in xylene, rehydrated through a graded series of alcohol washes and post-fixed in 4\% PFA. The sections were prehybridized in a humid chamber containing $50 \%$ formamide in $2 \times \mathrm{SSC}$ at $55^{\circ} \mathrm{C}$ for $30 \mathrm{~min}$. Digoxigenin (DIG)labeled RNA probes were pre-warmed at $85^{\circ} \mathrm{C}$ and hybridized to the sections overnight at $65^{\circ} \mathrm{C}$. We also performed negative staining using a sense probe and positive reactions did not appear (data not shown).

\section{RESULTS}

\section{Expression pattern of Fus during embryonic tooth development}

In the developing embryo, Fus was found to be highly expressed during early development, when all cells are rapidly proliferating and when expression becomes more restricted as the tissues differentiate (Alappat et al., 2003). To identify the spatial pattern of Fus expression, in situ hybridization was performed on serially sectioned embryonic teeth (from $11 \mathrm{dpc}$ to $16 \mathrm{dpc}$ ). Fus-specific expression was detected in the developing tooth.

During early tooth development (at $11 \mathrm{dpc}$ ), Fus was expressed in the dental lamina and the presumptive dental mesenchyme of the developing tooth (Fig. 1A). Furthermore, Fus was distributed in the dental epithelium and dental mesenchyme (Fig. 1B). Interestingly, at the beginning of the cap stage (14 dpc), Fus showed strong expression in the cervical loops of the dental epithelium, where a high level of cell proliferation continues to occur, as well as in the subjacent dental mesenchyme. On the other hand, weak expression was detected in the enamel knot, which represents a subset of epithelial cells that have escaped the cell cycle (Fig. 1C). At 16 dpc, Fus expression was maintained strongly in the dental papilla and the cervical loops (Fig. 1D). The observed expression pattern of Fus in the early tooth germ is consistent with a previous study (Alappat et al., 2003).

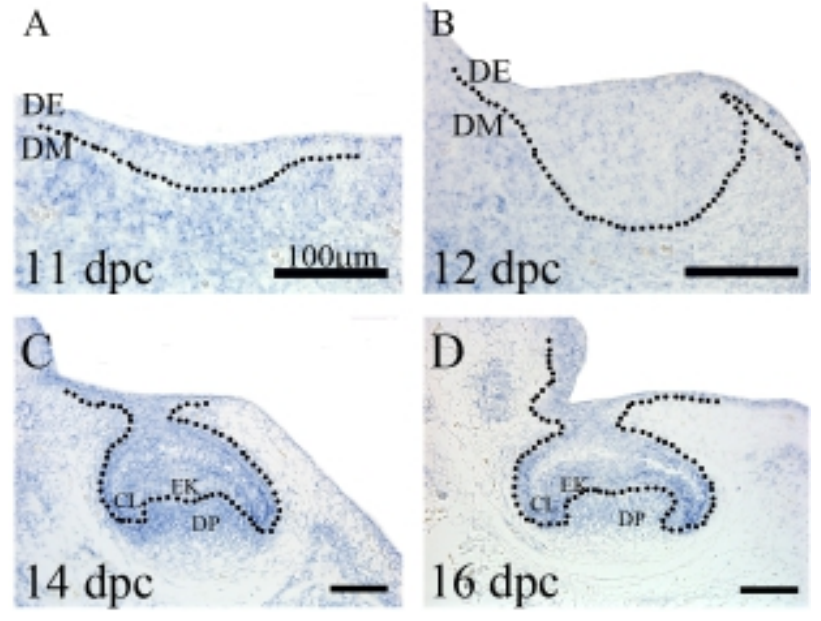

Fig. 1. Expression pattern of Fus in early tooth development.

(A) At $11 \mathrm{dpc}$, Fus was expressed in the dental lamina and the presumptive dental mesenchyme of the developing tooth. (B) At $12 \mathrm{dpc}$, Fus expression was shown in the dental epithelium and dental mesenchyme. (C) At $14 \mathrm{dpc}$, Fus was strongly expressed in the cervical loop of the dental epithelium but was weakly expressed in the enamel knot. (D) At $16 \mathrm{dpc}$, Fus expression was maintained strongly in the dental papilla and cervical loops. Dental epithelium (DE), dental mesenchyme (DM), cervical loop (CL), enamel knot (EK), dental papilla (DP). (Scale bar $=100 \quad$ ).

\section{Expression pattern of Fus during postnatal tooth} development

In order to understand postnatal molar tooth development in vivo, the histological appearance of sagittal sections of the mouse mandible at PN4 and PN14 was observed by HE staining. At PN4, odontoblasts and ameloblasts were present in the crown (Fig. 2A and C). In addition, the cervical loops were found in the apical region. At this stage, the HERS, the bilayered structure derived from the inner and outer enamel epithelium that fuses below the level of the cervical loops of the crown, is not yet developed. At PN4, Fus mRNA was expressed in the ameloblasts, not only around the cusp tip but also in the cervical loop (Fig. 2B and D). Fus was also expressed in the odontoblasts, the proliferation zone of pulp and the epithelial diaphragm.

At PN14, the first, second, and third molars showed different stages of root development. The crowns of the 


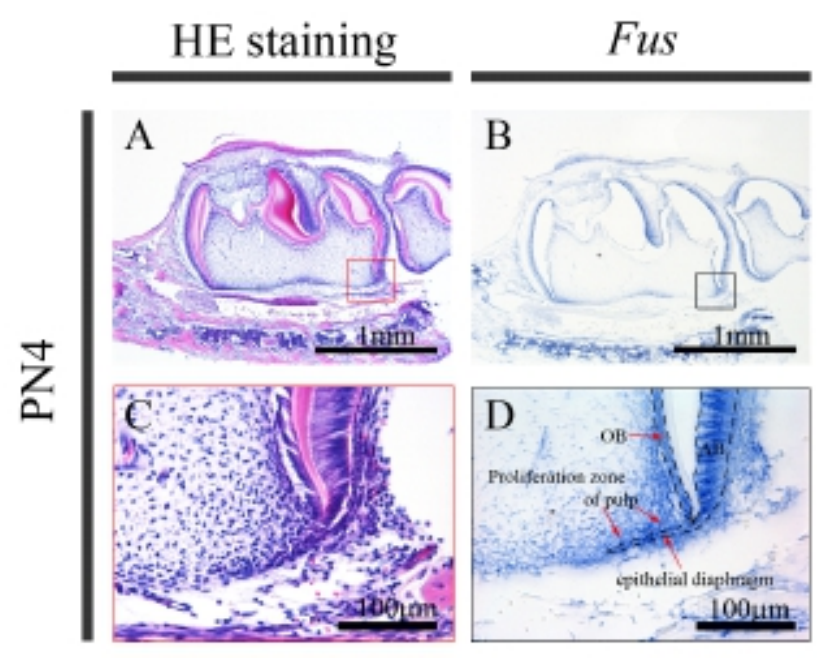

Fig. 2. Expression pattern of Fus in tooth development at PN4.

(A) HE staining of a sagittal section of the mouse mandible at PN4 (C shows a higher magnification image of the apical end of the root). (B) Fus mRNA was expressed in the ameloblasts, not only around the cusp tip but also in the cervical loop. Fus was also expressed in the odontoblasts, the proliferation zone of the pulp, and the epithelial diaphragm (D shows a higher magnification image). Odontoblast (OB), ameloblast (AB). (Scale bars $=1 \mathrm{~mm}(\mathrm{~A}, \mathrm{~B})$ and $100 \quad(\mathrm{C}, \mathrm{D}))$.

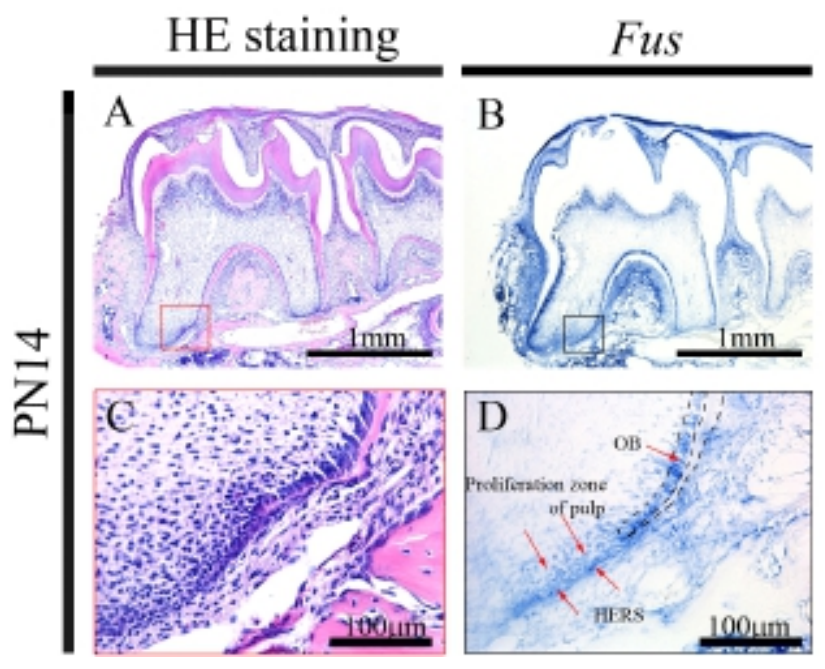

Fig. 3. Expression pattern of Fus in tooth development at PN14.

(A) HE staining of a sagittal section of the mouse mandible at PN14 (C shows a higher magnification image of the apical end of the root) (B) The odontoblasts maintained the expression of Fus. (D) Fus expression was observed in the dental pulp. Fus mRNA continued to be strongly expressed in the HERS (arrow). Odontoblast $(\mathrm{OB})$, ameloblast $(\mathrm{AB})$. (Scale bars $=1 \mathrm{~mm}(\mathrm{~A}, \mathrm{~B})$ and $100 \quad(\mathrm{C}, \mathrm{D}))$. first and second molars were almost fully developed, and the roots of these molars were developing (Fig. 3A and $\mathrm{C}$ ). At the apical end of the growing root, the HERS was detectable. At this stage, the odontoblasts maintained the expression of Fus (Fig. 3B and D). In addition, Fus expression was observed in the proliferation zone of the dental pulp and remained strongly in the HERS.

\section{DISCUSSIONS}

Many genes are involved in normal tooth development, and mutational analyses of these genes have revealed how tooth development is regulated (Thesleff et al., 1997).

FUS, a RNA/DNA binding protein, has been suggested to play a role in regulating cell proliferation and differentiation in the neovasculature of developing tumors in the rat brain and in endothelial cells (Blank et al., 2001; Alliegro \& Alliegro, 2002). Due to their complex nature, teeth are precisely controlled by congruent genetic and environmental regulation. Not much is known about Fus, not only with respect to its expression pattern but also its function and its role in normal tooth development. Therefore, using mice as a model, the goal of this study was to determine the expression pattern of Fus during the embryonic and postnatal stages of tooth development. Our results showed that Fus is expressed in the tooth bud from the initiation of tooth development (11 dpc). It is expressed in both the dental epithelium and the dental mesenchyme and is expressed particularly strongly in the cervical loops of the dental epithelium from the cap stage $(14 \mathrm{dpc})$. Thus, the expression pattern of Fus correlates with early tooth development.

The genetic relationship in tooth root development has been examined (Hosoya et al., 2008). However, the relationship between Fus and other genes in root development has not yet been extensively assessed. Here, we examined the expression pattern of Fus at the apical end of the tooth germ during root development. Fus was 
detected in the odontoblasts and ameloblasts at PN4. Fus expression was maintained in the odontoblasts, dental pulp, and especially in the HERS at PN14. Therefore, the expression pattern of Fus indicates that this gene may be involved in the HERS during root development. Further studies are required to examine the function and role of Fus in root development. Moreover, its relationship with other genes should be studied with respect to this process.

\section{ACK NOWLEDGEMENTS}

We are grateful to Sun-Kyoung Kim for helping experiments. This work was supported under the framework of international cooperation program managed by the National Research Foundation of Korea (NRF-616-20113-E00014).

\section{REFERENCES}

Alappat AR, Zhang M, Zhao X, Alliegro MA, Alliegro MC, Burdsal CA (2003) Mouse pigpen encodes a nuclear protein whose expression is developmentally regulated during craniofacial morphogenesis. Dev Dyn 228:59-71.

Alliegro MC, Alliegro MA (1996). A nuclear protein regulated during the transition from active to quiescent phenotype in cultured endothelial cells. Dev Biol 174:288-297.

Alliegro MC, Alliegro MA (2002) Nuclear injection of anti-pigpen antibodies inhibits endothelial cell division. J Biol Chem 277:19037-19041.

Aman P, Panagopoulos I, Lassen C, Fioretos T, Mencinger M, Toresson H, Höglund M, Forster A, Rabbitts TH, Ron D, Mandahl N, Mitelman F (1996) Expression patterns of the human sarcoma-associated genes FUS and EWS and the genomic structure of FUS. Genomics 37:1-8.

Bertolotti A, Bell B, Tora L (1999) The N-terminal domain of human TAFII68 displays transactivation and oncogenic properties. Oncogene 18:8000-8010.

Blank M, Weinschenk T, Priemer M, Schluesener H (2001) Systematic evolution of a DNA aptamer binding to rat brain tumor microvesses, selective targeting of endothelial regulatory protein pigpen. J Biol Chem 276:16464-16468.

Crozat A, Aman P, Mandahl N, Ron D (1993) Fusion of CHOP to a novel RNA-binding protein in human myxoid liposarcoma. Nature 363:640-644.

Dormann D, Haass C (2013) Fused in sarcoma (FUS): An oncogene goes awry in neurodegeneration. Mol Cell Neurosci, in press.

Eblaghie MC, Song SJ, Kim JY, Akita K, Tickle C, Jung HS (2004) Interactions between FGF and Wnt signals and Tbx3 gene expression in mammary gland initiation in mouse embryos. WormBook 14:1-7.

Gerber WV, Vokes SA, Zearfoss NR, Krieg PA (2002) A role for the RNA-binding protein, hermes, in the regulation of heart development. Dev Biol 247:116126.

Hicks GG, Singh N, Nashabi A, Mai S, Bozek G, Klewes L, Arapovic D, White EK, Koury MJ, Oltz EM, Van Kaer L, Ruley HE (2000) Fus deficiency in mice results in defective B-lymphocyte development and activation, high levels of chromosomal instability and perinatal death. Nat Genet 24:175-179.

Hosoya A, Kim JY, Cho SW, Jung HS (2008) BMP4 signaling regulates formation of Hertwig's epithelial root sheath during tooth development. Cell Tissue Res 333:503-509.

Hosoya A, Lee JM, Kim JY, Jung HS, Cho SW (2009) Expression of p63 during early craniofacial development of the mouse embryo. Dev Reprod 13:89-95.

Kwiatkowski Jr TJ, Bosco DA, Leclerc AL, Tamrazian E, Vanderburg CR, Russ C, Davis A, Gilchrist J, Kasarskis EJ, Munsat T, Valdmanis P, Rouleau GA, Hosler BA, Cortelli P, de Jong PJ, Yoshinaga Y, Haines JL, Pericak-Vance MA, Yan J, Ticozzi N (2009) Mutations in the FUS/TLS gene on chromosome 16 cause familial amyotrophic lateral sclerosis. Science 
323:1205-1208.

Morohoshi F, Ootsuka Y, Arai K, Ichikawa H, Mitani S, Munakata N, Ohki M (1998) Genomic structure of the human RBP56/hTAFII68 and FUS/TLS genes. Gene 221:191-198.

Peng Y, Kok KH, Xu RH, Kwok KH, Tay D, Fung PC, Kung HF, Lin MC (2000) Maternal cold inducible RNA binding protein is required for embryonic kidney formation in Xenopus laevis. FEBS Lett 482:37-43.

Rabbitts TH, Forster A, Larson R, Nathan P (1993) Fusion of the dominant negative transcription regulator CHOP with a novel gene FUS by translocation $\mathrm{t}(12 ; 16)$ in malignant liposarcoma. Nat Genet 4:175-180.

Tanaka H, Abe K, Kim CH (1997) Cloning and expression of the quaking gene in the zebrafish embryo. Mech Dev 69:209-213.

Thesleff I (2000) Epithelial-Mesenchymal signaling tooth morphogenesis. J Cell Sci 116:1647-1648.

Thesleff I, Sharpe P (1997) Signaling networks regulating dental development. Mech Dev 67:111-123.

Vance C, Rogelj B, Hortobagyi T, De Vos KJ, Nishimura AL, Sreedharan J, Hu X, Smith B, Ruddy D, Wright
P, Ganesalingam J, Williams KL, Tripathi V, Al-Saraj S, Al-Chalabi A, Leigh PN, Blair IP, Nicholson G, de Belleroche J, Gallo JM (2009) Mutations in FUS, an RNA processing protein, cause familial amyotrophic lateral sclerosis type 6. Science 323:1208-1211.

Wakamatsu Y, Weston JA (1997) Sequential expression and role of $\mathrm{Hu}$ RNA-binding proteins during neurogenesis. Development 124:3449-3460.

Wu L, Good PJ, Richter JD (1997) The 36-kilodalton embryonic-type cytoplasmic polyadenylation elementbinding protein in Xenopus laevis in ElrA, a member of the ELAV family of RNAbinding proteins. Mol Cell Biol 17:6402-6409.

Zhang Y, Zhang Z, Zhao X, Yu X, Hu Y, Geronimo B, Fromm SH, Chen YP (2000) A new function of BMP4; dual role for BMP4 in regulation of Sonic hedgehog expression in the mouse tooth germ. Development 127:1431-1443.

Zinszner H, Sok J, Immanuel D, Yin Y, Ron D (1997) TLS(FUS) binds RNA in vivo and engages in nucleocytoplasmic shuttling. J Cell Sci 110:1741-1750. 